\title{
La acreditación: Una forma de estandarizar la educación
}

\author{
Alicia Vargas Porras
}

\begin{abstract}
Resumen: La acreditación surge en los países latinoamericanos bajo intereses claramente marcados por la coyuntura socioeconómica y política que se empieza a gestar en los años ochenta, en donde la mundialización de las actividades exige respuestas globales a las diversas acciones humanas. La educación superior, en ese contexto empieza a enfrentar una serie de demandas que resignifican su quehacer y una de ellas es la necesidad de realizar procesos de autoevaluación y autorregulación conducentes a la acreditación.

En la presente ponencia se analizan los orígenes, intenciones e intereses que impulsan procesos conducentes a la acreditación, en los sistemas de educación superior de los países latinoamericanos. Como proceso político educativo, la evaluación está marcada por intenciones e intereses que señalan un determinado camino para la acción educativa $y$, en ese sentido, se apuntan también algunos rasgos hegemónicos tendientes a homogenizar la educación superior de los países latinoamericanos. Así mismo se analiza tanto el discursos de la calidad como los criterios de genealogía fabril que de ahí se derivan y que se encuentran orientando algunos procesos evaluativos. Se concluye con una reflexión entorno a un concepto de calidad por construir, considerando para ello nuestro deber hacia el fortalecimiento del desarrollo integral de nuestras sociedades.
\end{abstract}

\section{El inicio de la acreditación}

Desde finales del siglo XIX y hasta la década pasada, la acreditación fue una actividad exclusiva de los Estados Unidos, que se desarrolló por un interés nacional, interno, contrario a lo que ha sucedido en Latinoamérica en donde ha surgido en el marco de la homogenización de la educación superior, como parte de los procesos de globalización que enfrentamos. La acreditación surge en Estados Unidos ante la iniciativa de las asociaciones profesionales -como en el caso de Medicina- por regular la calidad de las instituciones educativas y calificar las carreras, y ante la necesidad social de facilitar la ubicación universitaria de gran cantidad de estudiantes que se trasladaban de una región a otra.

En nuestros países latinoamericanos, no es sino hasta la década de 1980 en que empezamos a hablar de acreditación, en una coyuntura sociohistórica y económica particular. Fue en esa década cuando pasamos de la concepción del Estado de bienestar, benefactor y proteccionista, que avalaba una educación democrática y pluralista, a enfrentar en los 80 , un período de aguda recesión económica ocurriendo además un retroceso de los logros que en materia de desarrollo social se había alcanzado. Se pasa entonces del estado benefactor 
al estado neoliberal y desde esta última perspectiva se busca disminuir el "tamaño" del mismo, fortalecer las reglas de la oferta y la demanda dentro de una racionalidad económica y se enfatiza el manejo de la ciencia y la tecnología, para obtener el ansiado desarrollo. La crisis económica repercute en la educación superior y en este sentido, como lo indica Rodríguez, (1995) los sistemas universitarios en América Latina resultaron receptores de una diversidad de presiones y nuevas demandas cuya confrontación estableció las orientaciones y los límites de las estrategias que se adoptaron en los ochentas. (P. 16)

Es en la década de los ochenta cuando se empieza a tildar de ineficiente a la universidad pública, a cuestionar el apoyo de fondos estatales para la educación terciaria y a impulsar, como positivos, aquellos intentos de agilizar y promover una educación superior tecnocrática que permita la incorporación rápida y eficiente de los graduados al mercado laboral.

Por esa época también empiezan a proliferar, en el nivel latinoamericano, las universidades privadas que florecen sin control en toda la región. Este fenómeno no es casual sino que obedece a la necesidad de responder a un mercado laboral de manera rápida, con carreras de enfoque eficientista, atendiendo además un deseo generalizado en la población de obtener un título universitario el cual, en épocas pasadas posibilitó el avance en la escala socio-económica, situación que no necesariamente ocurre en la actualidad. Para los gobiernos, enfrentados a problemas financieros, la proliferación de universidades privadas significó un respiro a las demandas crecientes de una población en aumento que presionaba por alcanzar la educación superior.

La década de los 90, nos enfrenta a una serie de procesos de internacionalización y de integración económica, social, polí- tica y cultural que se han cobijado bajo el nombre de "globalización" y que han impactado todos los ámbitos, en especial el económico y el cultural. Ante la "globalización" la educación cobra un papel estratégico para el desarrollo de los países, pero además, como parte de esas tendencias, también se busca uniformidad en los sistemas educativos, educación eficiente y que responda ágilmente a los intereses del mercado, y se agudiza la necesidad de establecer mecanismos que agilicen el tránsito de profesionales y la equiparación profesional entre países, atendiendo a demandas de nuevos tratados comerciales como los del Libre Comercio.

En los últimos años, especialmente a partir de la década de los noventa, se ha venido promocionando en nuestra región latinoamericana, el interés por establecer sistemas de acreditación para la educación superior que den fe del funcionamiento de los programas y las instituciones. Paralelamente además, se menciona la necesidad de abordar la calidad de la educación y se enfatiza el hecho de que, sin un proceso de autoevalaución que culmine con una acreditación, no será posible obtener la calidad de la educación necesaria para incursionar adecuadamente en un mercado laboral en el marco de la globalización.

Este énfasis en la acreditación, por lo tanto, no es un elemento que se incorpora a la educación superior de forma ingenua sino que es provocado por un cambio en las relaciones de la universidad con la sociedad y el estado, así como por la reestructuración de la economía mundial, la influencia de las corporaciones transnacionales, la revolución tecnológica y de las comunicaciones, y el fortalecimiento de una integración regional no sólo en términos económicos sino también sociales y culturales.

La acreditación ha surgido en nuestros países en un tejido de fuerzas económicas, sociales y políticas que conviene 
considerar para no caer únicamente en posiciones reactivas ante lo que sucede. El análisis crítico de la acreditación implica una comprensión de la educación como procesos sociohistórico y político, y la posibilidad de construir formas alternativas para participar, reflexivamente en los procesos evaluativos, sean éstos conducentes o no, a la acreditación, considerando así nuestras necesidades e intereses nacionales y sin perder de vista el aporte que la educación superior debe brindar al desarrollo integral de los pueblos.

\section{¿Qué entendemos por acreditación?}

La acreditación es un estado otorgado a una institución educativa o a un programa que se considera ha satisfecho o superado los criterios establecidos de calidad educativa (New England Association of Schools and Colleges).

"se basa, normalmente, en la verificación de los resultados del autoanálisis o autoevaluación que realiza una institución. Esta verificación es hecha por un organismo acreditador externo, de acuerdo con normas establecidas y el cual es reconocido por las instituciones incorporadas al sistema, quienes aceptan acogerse a él" (CINDA, 1993, p. 24).

Estos conceptos evidencian aspectos fundamentales de la acreditación, conforme se percibe actualmente:

- La verificación de resultados. Se habla de la necesidad de rendir cuentas, demostrar que se hace un uso adecuado de los recursos asignados y de ofrecer evidencias sobre el cumplimiento de las demandas impuestas a la institución de educación superior por la sociedad.

- Autoanálisis o autoevaluación. Las instituciones que se aboquen a un proceso conducente a la acreditación realizan un proceso interno de eva- luación, considerando para ello los factores, criterios de calidad, indicadores y pautas que establezca el ente acreditador.

- Un organismo acreditador externo. Una institución no puede autoacreditarse sino que debe rendir cuentas ante un organismo al cual las universidades han decidido incorporarse voluntariamente.

- Normas establecidas. Existen una serie de elementos previamente establecidos que enmarcan el proceso de evaluación interna y que evidencian si la institución (o el programa) es acreditable.

Se menciona que el proceso de autoevaluación para la acreditación es voluntario pero al respecto es necesario recordar que en algunos países (Chile, México) la obtención de la acreditación condiciona el financiamiento de programas académicos (investigación o apoyo docente).

\section{Etapas de la acreditación}

A grandes rasgos, un proceso conducente a la acreditación considera las siguientes etapas:

1. Evaluación interna de la institución o programa, de acuerdo con las normas establecidas por el ente acreditador.

2. Preparación de un informe el cual es sometido al ente acreditador.

3. Visita de un equipo de colegas educadores (pares externos) para comprobar los resultados de la evaluación interna que se expresan en el informe.

4. Preparación y discusión del informe por parte de los pares e implementación de acciones (otorgamiento de la acreditación o planteamiento de aspectos por mejorar. 
La acreditación persigue dos propósitos fundamentales que son:

- Asegurar la calidad de la institución o del programa (otorgada por el ente acreditador).

- Fomentar el mejoramiento de las instituciones o programas mediante planes de autorregulación interno que permitan corregir aspectos detectados como limitantes o contrarios al buen funcionamiento de la institución o programa y por el establecimiento de evaluaciones periódicas, ya que la acreditación no es una condición permanente sino que es dada por un período definido (3 a 5 años).

\section{¿Cómo se está desarrollando la acreditación de instituciones de educación superior en Costa Rica?}

En nuestro país, como en otros países latinoamericanos, la acreditación ha tomado fuerza impulsada fundamentalmente por las siguientes razones:

- La rendición de cuentas.

- La búsqueda de la calidad de los servicios que brinda la universidad.

- Los tratados de Libre Comercio.

- El caótico desarrollo de universidades privadas.

1. Rendición de cuentas: Con respecto a la rendición de cuentas, se aduce que la acreditación es una forma de mostrar cómo y en qué se invierten los recursos asignados a las universidades públicas. A la vez, existe la necesidad social y laboral de establecer formas mediante los cuales las instituciones se vean obligadas a aportar evidencias con respecto a la formación que reciben sus estudiantes y a la preparación de sus profesionales.
2. La búsqueda de la calidad: La calidad es un término que se popularizó en la industria, a partir de los años 50 con la incorporación del "Control Total de Calidad" a la administración empresarial. En este ámbito, es factible reconocer las características de un producto de calidad pero, al trasladar el concepto a la esfera educativas, encontramos la imposibilidad de reducir los procesos simbólicos que subyacen el proceso educativo a magnitudes y resultados observables. Las instituciones de educación superior han hecho un esfuerzo por ubicar indicadores de calidad que se ajusten a su naturaleza sui generis y así han incorporado a la evaluación, criterios para estimar esa calidad pensada en términos empresariales, tales como: Pertinencia, eficiencia, eficacia, efectividad, relevancia, universalidad, equidad, transparencia, entre otros, pero han quedado por fuera otros criterios importantes tales como igualdad, solidaridad, bien común.

3. Los tratados de libre comercio y la movilidad de profesionales: Los tratados de Libre Comercio requieren que los graduados procedan de programas acreditados por agencias no gubernamentales y en ese sentido están ejerciendo una presión para que los estados busquen estándares sustancialmente equivalentes. Por su parte, la movilidad profesional -dentro y fuera de esos tratadosobliga a que las carreras tengan estándares equiparables.

4. Orden a la proliferación de instituciones de educación superior privada: Finalmente, con respecto a la necesidad de poner orden a la proliferación caótica de instituciones de educación superior privadas, varios países de la región incluyendo el nuestro, han 
buscado en la acreditación una forma de estimar la calidad de esas instituciones. En Costa Rica, las instituciones de educación superior han crecido en forma desmedida. Por espacio de diez años, de 1975 a 1985 la UACA fue la única institución privada en el país. De 1985 a 1993, en ocho años, se crearon 19 más. De 1994 a 1997, en tres años se adicionaron 26 más y hoy hay más de 50. El CONESUP, que es el órgano encargado de controlar la apertura y funcionamiento de esas instituciones, se ha declarado incapaz de hacerlo por falta de personal y de recursos, y la Sala Cuarta ha dictaminado a favor de la libertad de enseñanza con lo que los controles son casi nulos. La acreditación se ha visto como una forma de que esas instituciones den fe de la calidad de sus servicios.

\section{Consideraciones para una lectura crítica de la acreditación}

Asociado al enfoque administrativo del control total de calidad, la autoevaluación y autorregulación se conciben como formas necesarias para organizar y corregir los procesos educativos bajo un concepto de educación en donde las relaciones sociales se ven en forma individual, particular y descontextualizada. Como menciona Da Silva (1997), surgen en la educación intenciones de control y autocontrol, de regulación y autorregulación en donde los procesos educativos se organizan en torno al mercado y a los objetivos y valores de la empresa capitalista. La idea de la autoevaluación como proceso participativo, de libre elección, de autodeterminación es erosionada al establecerse previamente mecanismos de contención y de control que guían los procesos evaluativos. Por decirlo de una forma gráfica, la cancha está marcada, las reglas del juego están establecidas, pero los jugadores tienen la oportunidad de evidenciar en el juego el estilo que deseen...

Dentro de esos procesos de control evaluativo florecen en todo Latinoamérica los sistemas de acreditación que pretenden evidenciar los procedimientos con que cuenta cada país para determinar y asegurar la calidad de sus instituciones o programas de formación profesional o técnica. En este aspecto de asegurar la calidad todos podemos estar de acuerdo, pero sin embargo, es necesario situar el problema en sus justos términos.

Baste un análisis de las publicaciones del Banco Mundial para comprender que existe un claro interés por la homogeneización educativa, mediante sistemas de control a través de la evaluación. La publicación de La enseñanza superior: Las lecciones derivadas de la experiencia (Banco Mundial, 1995) señala la crisis de las instituciones de educación superior en el nivel mundial evidenciada en una serie de problemas y limitaciones. El informe mencionado indica que esta crisis tuvo efectos graves, especialmente para los países en desarrollo, en donde las limitaciones presupuestarias y el aumento en la demanda se tradujo en hacinamiento, deterioro de la infraestructura, falta de recursos y disminución de la calidad de la enseñanza y las actividades de investigación.

Ante esta situación, el Banco Mundial propone cuatro enfoques básicos para la educación superior que tienen que ver con: Una mayor diferenciación entre instituciones de educación superior, incentivos para que las instituciones públicas diversifiquen sus fuentes de financiamiento, la redefinición del papel del Estado en la educación superior, y la introducción de políticas que busquen el logro de los objetivos de calidad y equidad. De esta forma, la 
solución a los problemas de la educación superior en el tercer mundo se aisla de otros aspectos que la afectan y que se relacionan con las desigualdades existentes en y entre los países, provocadas por el nuevo orden mundial centrado en los intereses y en los vaivenes del mercado internacional. A su vez, la consideración de diversificar las fuentes de financiamiento conlleva el predominio de fuerzas foráneas a la universidad, las cuales, al financiar proyectos, son capaces de mantener el control de determinados asuntos universitarios.

Los problemas de control y mejoramiento de la calidad continúan siendo parte de la agenda de organismos internacionales y baste una mirada a las páginas WEB para darnos cuenta de la cantidad de redes, periódicos y boletines internacionales que buscan examinar cuestiones relacionadas con el control de calidad, dentro de una concepción pragmática de la universidad en donde la educación superior es juzgada en términos de productos y de la contribución que aporte al desarrollo nacional. Como menciona Gibbons la calidad de la educación superior deberá considerar una serie de criterios que van más allá del tradicional quehacer institucional. De esta forma,

"Además del criterio del interés intelectual y su interacción, se plantean otras interrogantes: si se encuentra una solución, ¿será competitiva en el mercado? Será eficaz en función de sus costos? ¿Será aceptable socialmente?... Se está estudiando una variedad mucho mayor de factores en el marco de los procedimientos de control de calidad que actualmente se encuentran en gestación. Las universidades no podrán insistir en favor de criterios que reflejan únicamente sus intereses intelectuales; serán, en cambio, uno de entre tantos otros actores y el reto para ellas será lograr que sus legítimos intereses sobrevivan el proceso de negociación" (Gibbons, citado por El-Khawas, et al., 1998: 12).

¿Qué intenciones guardan esos procesos de evaluación para el control de la calidad universitaria? Se menciona por ejemplo, la necesidad de contar con listas de instituciones clasificadas, de acuerdo con indicadores de calidad, por región, país e inclusive a nivel mundial, en cuanto a una gama de misiones de conocimiento. O bien, la necesidad de acelerar la transición de una labor centrada en el contexto a una centrada en el aprendizaje para lo cual se hace necesario "adoptar decisiones sobre los objetivos de aprendizaje que deberán evaluarse y sobre las pruebas indicadoras del logro de dichos objetivos" (ElKhawas et al.; 1998:16), lo cual conlleva a una evaluación de productos. Y también estos autores mencionan la necesidad de establecer métodos de convalidación de títulos para la movilidad de estudiantes.

El interés por crear sistemas de autoevaluación y autorregulación surge, en nuestro país como procesos necesarios para prepararnos para la acreditación. Sin embargo, es conveniente recordar que dichos procesos están sostenidos por intereses claros tendientes a homogenizar la educación superior. Estamos ante la "educación transnacional" la cual se ampara por los tratados de libre comercio y por otros espacios de la globalización económica que promueven el aseguramiento de la calidad educativa, de acuerdo con las nuevas reglas del mercado globalizado.

Como se menciona en las páginas WEB del Center for Quality Assurance in International Higher Education (CQAIE) (www.cqaie.org/transnational.htm), el mercado global y las nuevas tecnologías están contribuyendo a la rápida globalización de la educación superior y por lo tanto es necesario que la fuerza profesional que preparen esas instancias sea "internacionalizable" y capaz de producir en un ambiente global. En este sentido se busca el aseguramiento de la calidad tanto en la formación como en la práctica profesional, de acuerdo con las fuerzas que reconfiguran la comunidad global mediante sistemas aceleradores del proceso como los tratados multinacionales de 
comercio y las nuevas tecnologías, los cuales fortalecen un nuevo paradigma para las profesiones en donde ya no cabe preguntarnos "por qué debemos globalizarnos" sino "cómo debemos globalizarnos". El CQAIE recomienda, a las universidades globalizadas, lo siguiente:

- Identificar los países en donde sus miembros pueden realizar prácticas profesionales.

- Facilitar el acceso de profesionales internacionales a espacios de práctica local.

- Asegurarse de que sus programas de educación superior sean de clase mundial y puedan llenar los estándares internacionales.

- Proteger a los consumidores al mismo tiempo que se mantiene la calidad de la educación superior y la práctica.

- Se recomienda, en resumen, aclarar y tomar en consideración las nuevas reglas del mercado global ${ }^{1}$.

En los últimos años, la relación universidad, sociedad y Estado ha cambiado en medio de la reestructuración de la economía mundial, la influencia de las corporaciones transnacionales, la revolución tecnológica y de las comunicaciones y la integración regional en términos económicos, sociales y culturales. La evaluación se nos presenta como forma de control y única solución para "ajustar" el sistema universitario a las actuales políticas económicas neoliberales al considerar, en el análisis de la calidad universitaria, indicadores de carácter neofuncionalistas, eficientistas, cortoplacistas y rentables. La claridad del uso de la acreditación se empieza a dibujar en el contexto de los tratados de libre comercio, como comentábamos anteriormente, pues las disposiciones de esos tratados enfatizan la necesidad de "establecer criterios objetivos para la autorización del libre tránsito de servicios profesionales, centrados en requisitos de educación, experiencia, evaluación y ética” (Lemaitre, 1999 p. 244).

De esta forma, en los albores del siglo XXI el sentido de la educación se vuelca hacia una perspectiva productivista que coloca al empleo como punto central del fin educativo y en la década de los años 90 vemos la consolidación del pensamiento global de la educación que se basa en la libre competencia y la libre empresa, desde la perspectica neoliberal. Este aspecto ha entrado en contradicción con la función social de la educación en general y de la educación superior en particular, en donde se busca la preparación de profesionales para las transnacionales, mediante empleos puntuales y específicos que desestiman aquellos aspectos que no contribuyan a la dinámica laboral del quehacer transnacional. (Díaz, 1995).

Los nuevos significados que sustentan los discursos mencionados evidencian una cultura evaluativa en construcción que privilegia la normalización, la estandarización, la prescripción de lo correcto de acuerdo con los intereses transnacionales.

En los términos expuestos, la homogenización de la educación puede entonces llevarnos a reaccionar en el presente y a construir un futuro desde la perspectiva e intereses de los grupos privilegiados y poderosos. Los intereses por crear sistemas de acreditación deben ser analizados con cuidado pues subyacen ahí intenciones por uniformar la cultura y sustraerla del tejido político que la nutre y la conforma, desdibujando así, -mediante la educación- las diferencias, los intereses y las identidades nacionales. En este marco, la pedagogía llega a ser considerada como un cuerpo de conocimientos que ha sido previamente definido por entes foráneos y nos conduce a una educación no 
problematizadora, en tanto que obedece a cánones externos. No hay espacio entonces para cuestionar las contradicciones nacionales e internacionales que están provocando inequidades, injusticias, desigualdades cada vez más profundas pues, la práctica pedagógica se asila de los procesos políticos y culturales, y por lo tanto quedan por fuera la consideración de las relaciones asimétricas de poder que promueve la globalización económica.

Por su parte, la evaluación y la acreditación, si son tejidas alrededor de los discursos de calidad, rendición de cuentas y autorregulación, nos conducen a la consolidación de una educación superior definida (y juzgada) con parámetros que fortalecen fundamentalmente los intereses transnacionales y la globalización económica. No son por lo tanto, procesos ingenuos.

\section{¿Cómo podemos pensar la acreditación desde nuestro contexto?}

No podemos sustraernos del acercamiento de las distancias, ni de la evolución de tecnología que ha permitido la agilidad, universalidad y enriquecimiento de la comunicación y del conocimiento. Tampoco podemos aislarnos de los procesos de integración regional ni negarle la oportunidad, a nuestros profesionales, de que ejerzan en espacios sin fronteras. Por lo tanto, hoy más que nunca tenemos la obligación de pensar una educación que permita fortalecer el desarrollo integral de nuestras sociedades. La educación, como disciplina social, no puede verse aislada del contexto socio-político, histórico y económico en donde se enmarca y, en este contexto, la evaluación y la acreditación educativas debemos pensarlas también, como formas de fortalecer la educación que permita fortalecer -de manera equitativa e igualitaria- a nuestras sociedades.
Es posible asumir los procesos evaluativos conducentes a la acreditación de una forma reflexiva pues, como proceso político educativo, la evaluación -mediante los criterios y los diferentes medios- es capaz de silenciar, promover, posibilitar, negar, afirmar, consolidar, retar, unas voces $u$ otras. De esta forma, desde una perspectiva crítica, requerimos abrir espacios para incorporar, en la evaluación, el análisis de aspectos tales como los siguientes:

- ¿Cómo pensamos la universidad pública desde nuestro contexto local?

- ¿Cómo fomentamos un mundo en donde quepamos todas y todos y, en ese contexto, qué tipo de universidad nos conviene promover?

- ¿Cuál es la relación que se busca entre la universidad y la sociedad civil y como trascendemos la tendencia actual de fortalecer una clara relación universidad-mercado?

- ¿Qué idea de educación superior necesitamos para enriquecer el desarrollo humano y trascender el concepto del capital humano como inversión?

- ¿Cómo enriquecer la pluralidad de los saberes, por encima de las fuerzas hegemónicas que impulsan la tecnocracia y el saber comercializable?

- $\quad$ Y si queremos buscar una educación de calidad dentro de un marco de la universidad humanista, cómo concebimos esa calidad?

Estas y otras interrogantes podrían guiar una discusión en tiempos en donde la acreditación transita por el camino de los productos medibles y los cuantificables, como aproximación académico-técnica con pretensiones de objetividad valorativa. 


\section{Nota}

1. Traducción libre de las páginas WEB: http:// www.cqaie.org/transnational.htm

\section{Referencias bibliográficas}

Asociación de escuelas e instituciones de enseñanza superior de Nueva Inglaterra, Inc. (New England Association of Schools and Colleges, Inc.). Manual provisorio de evaluación. Uso interno. (mimeogr.). 1993.

Banco Mundial. La enseñanza superior: Las lecciones derivadas de la experiencia. (Publicación ISBN 0-82132773-9). Washington, D. C.: Banco Mundial. 1995.

Brunner, J. J. Experiencias latinoamericanas: El caso chileno. En H. M. Vessuri (Ed.), La evaluación académica. (Vol. 2, pp. 37-49). París: UNESCO. 1993.

Center for Quality Assurance in International Higher Education (CQAIE). (www.cqaie.org/transnational.htm), 2001.

CINDA. Acreditación universitaria en América Latina. Antecedentes y experiencias. México: ANUIES-OUI. 1993.

Da Silva, T. T. "El proyecto educativo de la nueva derecha y la retórica de la calidad total". En: Apple, M. W. Cultura, política y currículo. Ensayos sobre la crisis de la escuela pública. Buenos Aires: Editorial Losada, S. A. 1997.

Díaz B., Ángel. Empleadores de universitarios. Un estudio de sus opiniones. México: Universidad Nacional Autónoma de México, Centro de estudios sobre la Universidad. 1995.
El-Khawas, E., DePietro-Jurand, R. \& Holm-Nielsen, L. El control de calidad en la educación superior: Avances recientes y dificultades por superar. (www.worldbank.org/education/tertiary /quality.html). 1998.

Gurdián, Alicia. La acreditación universitaria en Centroamérica y el Caribe en el contexto mundial. Latin American Studies Association XIX Internatiohal Congress. Washington, D.C., 28-30 September, 1995. (Mimeografiado). 1995.

. "Ayer y hoy de la evaluación académica institucional en la Universidad de Costa Rica: Una propuesta." En: Séptimas jornadas de evaluación en la educación superior. Chile: Instituto de Educación, pp. 17-39. 1994.

Jofré, A. La universidad en América Latina: Desafios y estrategias para las próximas décadas. Cartago: Editorial Tecnológica de Costa Rica. 1994.

Kells, H. R. Procesos de autoevaluación. Una guía para la autoevaluación en la educación superior. Perú: Pontificia Universidad Católica del Perú. 1997.

Lemaitre, M. J. “Acreditación: una experiencia de aprendizaje y el diseño de un nuevo sistema. El caso de Chile y el Consejo Superior de Educación”. En: L. Yarzábal, A. Vila y R. Ruiz (Editores). Evaluar para transformar. (Pp. 199-276). Venezuela: IESALC/UNESCO. 1999.

Rodríguez G., Roberto. "A dónde va la universidad latinoamericana?". En: J. E. Esquivel (Coordinador). La Universidad hoy y mañana. México: Universidad Nacional Autónoma de México, Centro de Estudios sobre la 
Universidad / Asociación Nacional de Universidades e Instituciones en Educación Superior (ANUIES). 1995.
Worthen, B. R. y Sanders, J. R. Educational evaluation: Alternative approaches and practical guidelines. New York: Longman. 1987. 